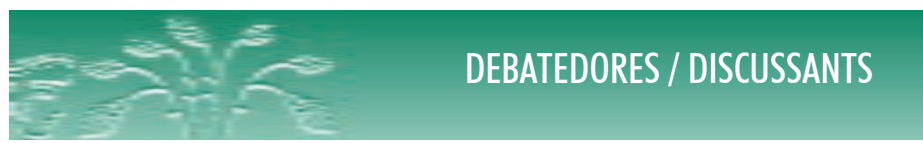

$10.12957 /$ demetra.2013.6902

\title{
Como pensar o capitalismo atual e suas consequências para o campo da nutrição sem recorrer à noção de estrutura?
}

\section{How to consider recent capitalism and its consequences for the field of nutrition without resorting to the notion of structure?}

Francisco Romão Ferreira'

' Departamento de Nutrição Social, Instituto de Nutrição. Universidade do Estado do Rio de Janeiro. Rio de Janeiro, RJ, Brasil.

Correspondência / Correspondence Francisco Romão Ferreira

E-mail:fromao@terra.com.br
Muito oportuno o texto "Estrutural - funcionalismo antropológico e comensalidade. Breves considerações sobre a mudança social" ao resgatar a concepção estruturalista na análise das relações sociais atuais, principalmente por apontar que a investigação de objetos de pesquisa no campo da Alimentação e Nutrição e das Práticas Corporais nem sempre deixam explícitosseus paradigmas teórico-metodológicos. Ou pior, muitas vezes essa perspectiva teórica é desprezada pelo campo da Nutrição que prefere estudos objetivos e quantitativos, mais adequados às publicações que pontuam mais na Capes.

Parece haver certo pudor por parte de alguns setores da academia em propor uma análise estruturalista, talvez porque ela não esteja mais em voga, como se a produção do pensamento tivesse que seguir "a última moda", assim como o mercado dos bens de consumo. Mas talvez essa também seja uma tendência do pensamento atual, de buscar um certo pragmatismo e produtivismo, coisificando e fragmentando tudo, transformando até o pensamento acadêmico em objeto de consumo. A necessidade de produção acelerada, a lógica da produtividade, medida apenas por critérios quantitativos talvez explique essa nova tendência do "mercado". Um produto antiquado como o estruturalismo não agradaria os consumidores atuais. 
Essa lógica do pensamento fastfood não combina com o rigor e a maturidade necessários para percebermos a sutileza oculta nos detalhes da vida social. Sua análise requer um tempo lento que permita a percepção dos sentidos ocultos ou dissimulados na realidade. Essa pesquisa etnográfica baseada em dados empíricos, esse olhar minucioso e perspicaz não combinam com a produção acelerada de textos, artigos, teses e dissertações. Perceber as minúcias da vida social requer uma leitura slowfood, ou seja, precisamos de tempo para perceber as estruturas sociais. Não dá para perceber ou organizar mentalmente tais estruturas numa lógica de pensamento fragmentado que não dá valor às grandes narrativas, como se elas tivessem desaparecido, como se o simples fato de deixar de percebê-las fizesse com que elas desaparecessem. Como uma criança que fecha o olho e acha que o objeto desapareceu. Mas no nosso caso as estruturas sociais continuam lá, no mesmo lugar, agindo e produzindo sentidos. Sendo assim, como pensar o capitalismo atual sem recorrer à noção de estrutura?

A tradição Estrutural-Funcionalista, bem apontada no texto de Cesar Sabino e Maria Claudia Carvalho, analisa as estruturas a partir de bases empíricas e dão ênfase às estruturas subjetivas e que levam à transformação social, mas a base da investigação é sempre a experiência cotidiana, pois como afirmam os autores, citando Francis Bacon, "nada existe na mente que não tenha passado antes pelos sentidos". Nesta tradição de pensamento os fenômenos sociais constituem uma classe distinta de fenômenos observáveis na sua existência cotidiana e as estruturas sociais são tão reais quanto os organismos individuais. Ou seja, para compreender as ações individuais é preciso então compreender também o conjunto de relações que compõem o sistema e para compreender a estrutura social é preciso compreender as ações individuais, perceber o "modo como essas partes componentes funcionam em relação a cada uma e em relação ao todo". Um dos autores citados no texto, o antropólogo Radcliffe-Brown, afirma que "também os fenômenos sociais em qualquer sociedade humana não são resultado imediato da natureza dos seres humanos tomados individualmente, mas consequência da estrutura social pela qual estão unidos”.

Mas sabemos que as estruturas sociais são totalidades organizadas segundo princípios internos que lhes são próprios e que comandam seus elementos ou partes, seu modo de funcionamento e suas possibilidades de transformação temporal ou histórica. Na estrutura, o todo não é a soma das partes, nem um conjunto de relações causais entre elementos isoláveis, mas é um princípio ordenador, diferenciador e transformador. Uma estrutura é uma totalidade dotada de sentido. A concepção estruturalista veio mostrar que os fatos humanos assumem a forma de estruturas, isto é, de sistemas que criam seus próprios elementos, dando-lhes sentido pela posição e pela função que ocupam no todo. Perceber uma estrutura, portanto, é perceber um modo de organização da realidade a partir de relações causais, aparentemente banais, mas que fazem sentido, ou melhor, que produzem os sentidos que dão sentido ao real.

A concepção estruturalista também requer, além do tempo lento, uma percepção da totalidade e das relações entre as partes que compõem a realidade social. São mecanismos sutis que se 
escondem em sistemas complexos de significação. A Antropologia Social mostrou que, ao contrário do que pensava a Antropologia Positivista, as chamadas "sociedades primitivas" não são uma etapa atrasada da evolução da história social da humanidade, mas uma forma objetiva de organizar as relações sociais de modo diferente do nosso, constituindo estruturas culturais. As sociedades urbanas complexas, do mesmo modo, produzem estruturas simbólicas que regulam a vida social.

A Antropologia expõe os sistemas de regras, valores, ideias e mitos ocultos no cotidiano que dão sentido às ações. Mas esta percepção implica numa imensa capacidade de decodificar dados aparentemente aleatórios e ordená-los segundo uma construção teórica coerente na qual as partes dão sentido ao todo. Outros autores estruturalistas produziram obras que até hoje são referências nas Ciências Humanas e Sociais. Saussure mostrou os complexos mecanismos da linguagem. Sapir mostrou como nossa visão de mundo depende da linguagem. Marx evidenciou o peso da estrutura econômica na construção do indivíduo. A Psicanálise mergulhou nosso olhar na estrutura inconsciente da personalidade. Bachelard nos colocou diante da história do saber como desenvolvimento descontínuo. São análises minuciosas da vida cultural que pretendem dar conta da totalidade do real e, para tal, demandam o tal tempo lento citado acima. Tempo este que não combina com a velocidade do nosso mundo líquido. Se Marx, Freud ou Saussure fossem pesquisadores atualmente, eles teriam que fatiar seus trabalhos para publicá-los em revistas Qualis $A$. Eles não poderiam pensar nas macroestruturas, pois seus trabalhos seriam considerados muito extensos e isso não resultaria em pontos suficientes.

Para o Estruturalismo Filosófico, a categoria ou ideia de fundo não é o Ser, mas a relação; não é o sujeito, mas a estrutura. Esta antecede o sujeito. A partir dessa perspectiva o pensador francês Michel Foucault (também considerado estruturalista) reestrutura as ideias de sujeito, sociedade, instituição, saber e poder. Para ele, as sociedades modernas apresentam uma nova organização do poder, que antes era visto como repressivo e negativo, percebendo que no capitalismo o modelo repressivo não é eficaz e, se os mecanismos de dominação fossem exercidos apenas de forma violenta, eles não seriam eficazes. Para Foucault, os mecanismos de poder se tornam mais sutis, naturais, "agradáveis e desejados". Segundo ele, é preciso cessar as contínuas descrições sobre os efeitos do poder em termos negativos: ele "exclui", "reprime”, "recalca”, "censura”, "discrimina”, "mascara", "esconde".

O poder produz/simula o real. Produz meios de dominar ideias, objetos, sentidos, conceitos e desejos. Ele captura os desejos e estabelece uma relação íntima com o saber, torna-se um produtor de saber, de conhecimento, cria efeitos de poder. Torna-se, portanto, produtivo, positivo. Mas ele não se reproduz a partir de um centro (do Estado, da classe dominante ou de um grupo de pessoas). Ele se reproduz a partir de micropoderes que se estendem sobre o social sem nenhum centro. Os mecanismos de dominação são mais sutis e se fazem aceitar pelos dominados. Constituem-se a partir de um número expressivo de táticas, normas eficazes, mecanismos disciplinares de controle e estratégias que garantem a dominação a partir dos próprios dominados. 
A ordem normativa não pretende reprimir, punir, proibir. Ela quer ser aceita e disseminada, quer convencer, seduzir. Sua tática é, portanto, convencer racionalmente, se apresentar como uma escolha mais lúcida, racional e agradável, escolhida pelos indivíduos e não imposta a eles. Se antes o poder era repressivo, proibitivo, punitivo e (como diria Durkheim) coercitivo, hoje é normativo, disciplinador, agradável, sutil, racional e "natural".

Relacionando essa reflexão ao campo científico da Nutrição podemos perceber essa mudança de concepção dos discursos que regulam a ordem alimentar e a produção de objetos de consumo no cotidiano, pois os alimentos também são símbolos, também possuem aura e produzem distinção social. Podemos então perceber movimentos aparentemente contraditórios, pois a flexibilidade das regras e normas convivem com as rígidas recomendações nutricionais. Ao mesmo tempo em que temos o controle da ordem alimentar (ditada pelas instituições científicas nutricionais) temos a oferta abundante de alimentos pelas grandes cadeias globais de fastfood; percebemos uma "valorização" dos produtos que traduzem a identidade local e uma padronização de gostos e produtos em escala global e temos uma oferta aparentemente crescente da escolha individual convivendo com a uniformização dos produtos das mesmas empresas transnacionais. A aparente capacidade de livre escolha do indivíduo serve também como função do sistema, posto que o mercado está pronto para atender (e produzir) seus desejos. Para pensar a ordem alimentar temos, então, que pensar o principal ator social que está por trás das ações cotidianas, ou seja, temos que pensar o papel do mercado. Este produz os elementos que organizam a estrutura simbólica que regula o consumo de alimentos e as relações sociais do nosso tempo.

Conforme dissemos anteriormente, o capitalismo global dissemina sua estrutura de poder/ pensamento por meio do discurso sutil, normativo, disciplinador, agradável, racional e "natural" do mercado. Seu poder simbólico e sua estrutura de produção de sentidos se manifesta no campo da Alimentação e Nutrição a partir de diferentes perspectivas. Entre elas: na medicalização da vida cotidiana (transformando os alimentos em medicamentos); nas estratégias de "Biopoder", controle disciplinar e docilização dos corpos "magros e saudáveis"; na estetização da Saúde que transforma parâmetros de beleza em indício de vida saudável; na erotização e medicalização de diferentes fases da vida; na mercantilização da Medicina, na coisificação dos afetos, dos desejos e das relações; na produção de alimentos que uniformizam e massificam os mesmos produtos em escala global; na aceleração dos processos sociais do mundo líquido que precariza as relações de trabalho; na mercantilização de dimensões simbólicas, culturais, sociais e religiosas em meros produtos; ou ainda, na necessidade imperativa de produtividade na construção dos saberes nas Ciências da Saúde. A lógica pragmática e utilitarista do mercado está presente em todas as relações sociais, inclusive as afetivas. 
Uma análise de cunho estrutural funcionalista na nossa sociedade hoje precisaria destacar o papel do consumo e das relações simbólicas que ele produz. Se fizermos um estudo etnográfico no entorno da Uerj para perceber os elementos da nossa "cultura local" veremos que ela é uma mosaico, uma bricolagem de sentidos que agrupa valores tradicionais e cotidianos e valores globais de mercado. Os mesmos elementos citados por Bourdieu para captar os jogos de distinção social em outras culturas poderiam ser utilizados aqui na esquina para perceber o quanto do poder simbólico do capitalismo global está presente aqui, bem diante de nós. Os códigos de ostentação social presentes em outras culturas são visíveis aqui, em plena Tijuca, logo aqui ao lado. Basta uma ida rápida ao Shopping Tijuca que encontraremos a "multiplicidade de ofertas individuais" proporcionadas pela globalização. Podemos "escolher" entre um lanche do McDonalds, um frango do KFC, uma pizza do Pizza Hut, um hambúrguer do Bob’s, do Burguer King ou do Subway. Temos também outras escolhas como a esfiha do Habib's, a comida do China in Box ou a comida japonesa da rede KoniStore. E depois ainda podemos tomar um café e comer um cupcakeno Starbucks (a maior rede de cafeterias do mundo).

Mas se não quisermos ir a um lugar "tão contaminado pela lógica capitalista" podemos ir a uma loja de doces qualquer e lá encontraremos um bom café espresso italiano Lavazza, e poderemos comer croissants, muffins, madeleines, financiers, cheesecakes, pastéis portugueses de Belém ou um brownie acompanhado de uma Coca Zero, afinal, é preciso cortar as calorias. Difícil vai ser encontrar um cajuzinho, um bolo de fubá, uma paçoca ou um pé de moleque.

Mas como pensar essa realidade tão próxima se nas Ciências da Saúde a abordagem estrutural funcionalista está fora de moda? Como pensar a estrutura simbólica do mercado se os textos "reflexivos e subjetivos" são mal avaliados? Como pensar a nossa realidade apenas a partir de estudos epidemiológicos, "neutros, pragmáticos e objetivos"?

Sabendo que as estruturas sociais continuam lá, no mesmo lugar, agindo e produzindo sentidos, só que agora sob a influência do capitalismo global, as perguntas que faço aos autores são:

Como abandonar o pensamento estruturalista se ele nos fornece a chave para compreender os jogos de poder do capitalismo?

Como pensar o capitalismo atual e suas consequências para o campo da Nutrição sem recorrer à noção de estrutura? 
